\title{
Jing-Jin-Ji Air-Rail Intermodality System Study Based on Beijing New Airport
}

\author{
Wen Liu, Ouyang Jie, Yanan Su \\ Airport College, Civil Aviation University of China, Tianjin, China \\ Email: suyanan14@163.com
}

Received 23 June 2015; accepted 15 October 2015; published 22 October 2015

\begin{abstract}
After the completion of Beijing New Airport, air-rail intermodality will become an important means of internal and external links in Jing-Jin-Ji Region. Jing-Jin-Ji Air-Rail Intermodality System is built and 7 sub-systems are divided based on user demand analysis. Refer to the passenger process, the business process of the system is planned and the sub-systems are described using data flow diagram. The system provides theoretical support for the development of air-rail intermodal in Jing-Jin-Ji region.
\end{abstract}

\section{Keywords}

Jing-Jin-Ji Region, Air-Rail Intermodality System, Business Process, Data Flow Diagram

\section{Introduction}

Construction of the Beijing New Airport started in December 26, 2014 and a comprehensive traffic network with which at the core will be built. The high-speed railway network of Jing-Jin-Ji core region will radiate to the whole northern area, in which the Beijing-Kowloon Passenger Line will directly connect in Beijing New Airport, Beijing Ben Thanh intercity railway line is also planning a direct link to Tianjin Airport. Railway lines, stations and airports of the Jing-Jin-Ji region will provide basic conditions for the development of air-rail intermodality.

However, there are many inconveniences in the current transportation process. So a complete air-rail intermodality system needs to be built by government from the management system [1], which could manage and maintain integrated ticketing, information query and update, meet the demands of various users, and ensure information security through security guaranty mechanism.

\section{User Analysis and System Division}

In the Jing-Jin-Ji air-rail intermodality system, we suggest choosing Beijing West Station, Beijing South Station, Tianjin Railway Station, Zhengding Airport Railway Station as trial operation railway stations, and enlarging the coverage to main stations along the rail lines after they operate normally. Beijing Capital Airport, Beijing New Airport, Tianjin Airport and Shijiazhuang Airport are chosen as operation airports. On the basis of current air-rail intermodal products, part of the airlines can participate in the trial operation, and other airlines can be absorbed into the service scope of Jing-Jin-Ji air-rail intermodality system later. 
The users of Jing-Jin-Ji air-rail intermodality system include customers and servers, among which passengers and partners such as distributors and information service providers and so on are customers, while administration departments, rail units, civil aviation units are servers. Customers and servers are respectively demand and supply side of the system. The specific user structure is shown in Figure 1.

According to demands of passengers and information management, the functions of Jing-Jin-Ji air-rail intermodality system should include user registration and query, auxiliary optimization decision, check-in and through baggage handling service, feedback service, information audit and management, information update and maintain, financial allocation, integrated ticketing and so on. U/C matrix is used to organize and solve these functions and data [2], dividing the sub-systems of Jing-Jin-Ji air-rail intermodality system.

Jing-Jin-Ji air-rail intermodality system could be divided into 7 sub-systems: Operation Service, Auxiliary Optimization Decision, Feedback Service, Integrated Ticketing, Through Baggage Handling, Financial Management and Information Management. Information flow relation between them is shown in Figure 2.

\section{Business Process Plan}

While building a system, the internal processes can be understood well through business diagrams and system can be optimized by correcting the problems and deficiencies. Therefore, it's necessary to plan the business process of Jing-Jin-Ji air-rail intermodality system. Combined with air-rail intermodal passenger process in Jing-Jin-Ji region, business process is planned step by step along the flow of information. Result is shown in Figure 3. In the future the business process can be adjust according to the implementation status of infrastructure and transport mode, on the basis of which the establishment of air-rail intermodality system can be optimized and improved.

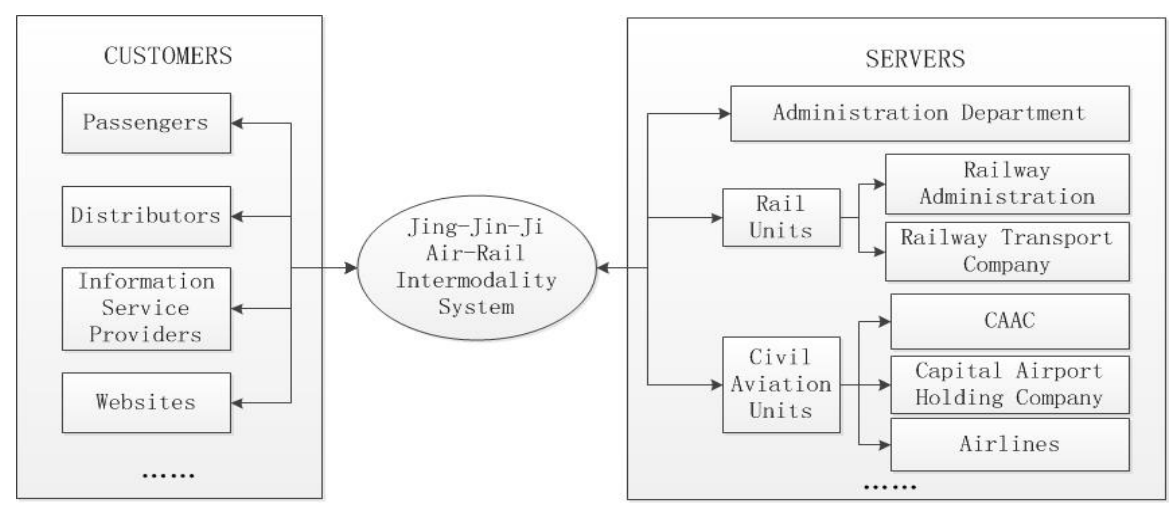

Figure 1. User structure of Jing-Jin-Ji air-rail intermodality system.

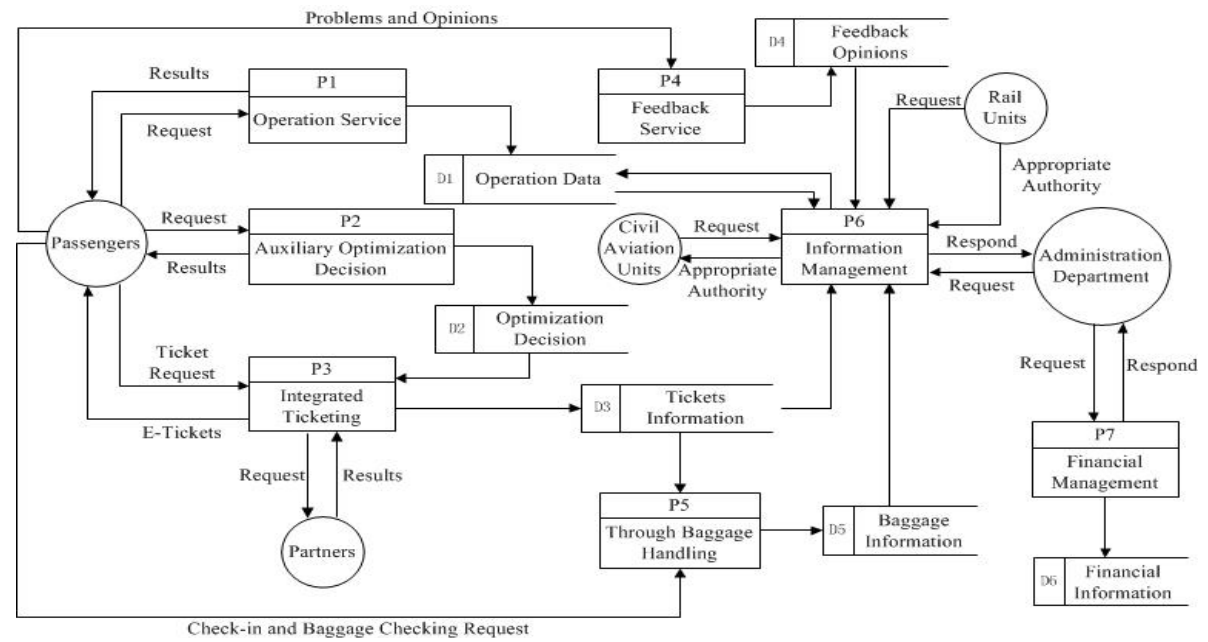

Figure 2. Information flow relation between the sub-systems. 


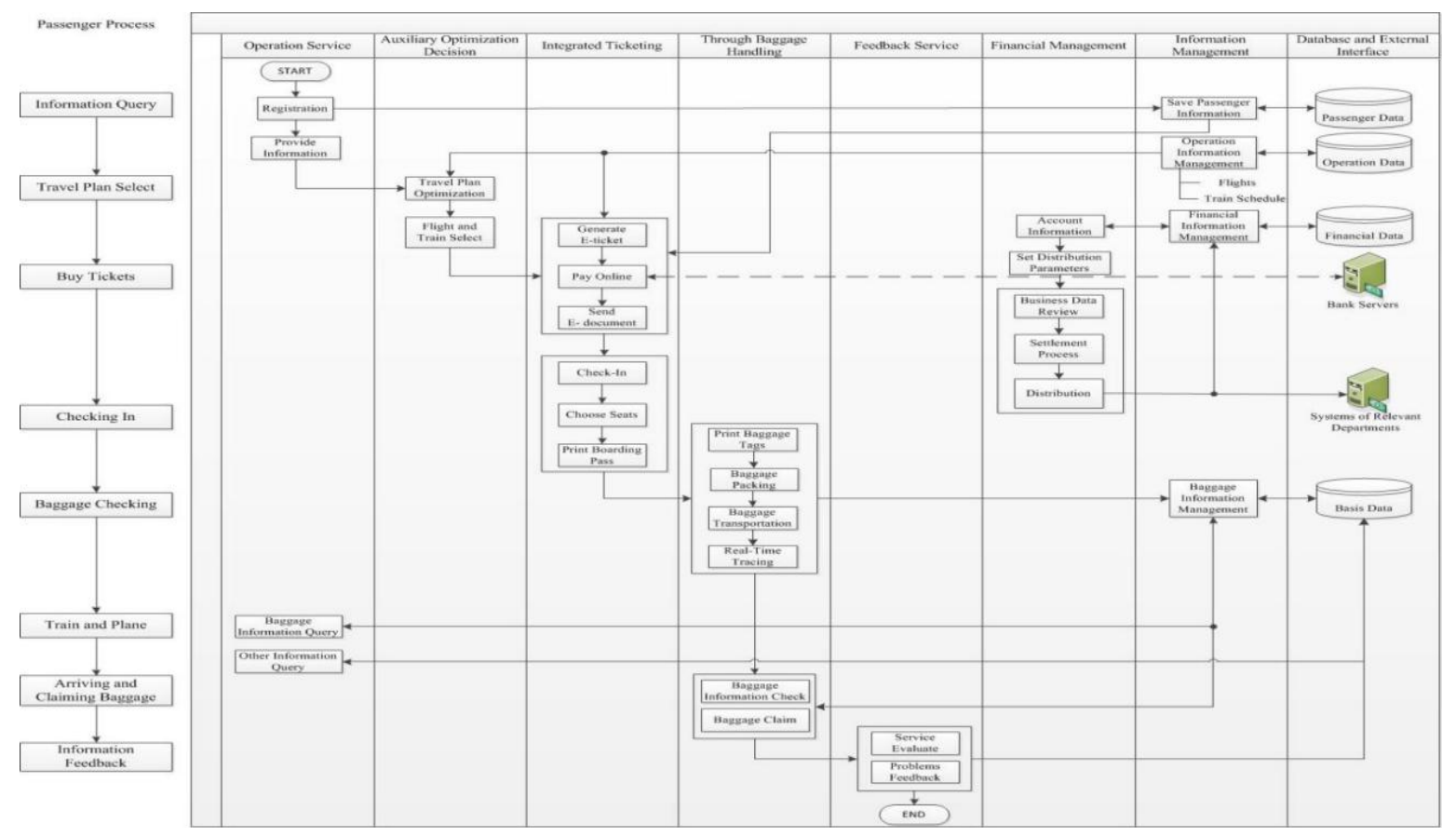

Figure 3. Business process of Jing-Jin-Ji air-rail intermodality system.

\section{System Structure}

Data flow diagram is the most common presentation to describe system structure [3], which describes the data flow and process in the system in the form of graphics and is a functional model to express the relations between system data input, output, storage and process. A specific data flow diagram describing air-rail intermodality system can be obtained by the principle of "From Outside to Inside".

\subsection{Operation Service Subsystem}

Operation Service Subsystem is the interface module for customers' access to air-rail intermodality system, which has three main functions: registration and login, information query, guide service. The specific structure is shown in Figure 4.

\subsection{Auxiliary Optimization Decision Subsystem}

Auxiliary Optimization Decision Subsystem could combine the process of train schedules and flights with mathematical optimization model calculation, and help passengers to make travel plans with optimization goal of passenger demands and constraints of fares, schedules, travel time and so on, using computer intelligent optimization technology. Result is shown in Figure 5.

\subsection{Integrated Ticketing Subsystem}

Integrated ticketing is needed in air-rail intermodality, when passenger just needs to buy one joint ticket to cover the whole travel process. Besides, the fare of the joint ticket is lower than two tickets separately. The rail units will set IATA codes for relevant railway stations and airlines could code-share with several stations according their own needs.

E-ticket is the mode of joint tickets, in which the following contents should be contained [4]: ticket serial number, passenger name, passenger ID number; name and code of origin station, name and code of destination station, ticketing date, ticketing station and code, valid date, connection information, fare, time, transfer information, baggage information and so on. Structure of integrated ticketing subsystem is shown in Figure 6.

The joint tickets will be sold by a unified ticket center and the earnings will be attached to the financial management subsystem to realize automatic clearing. 


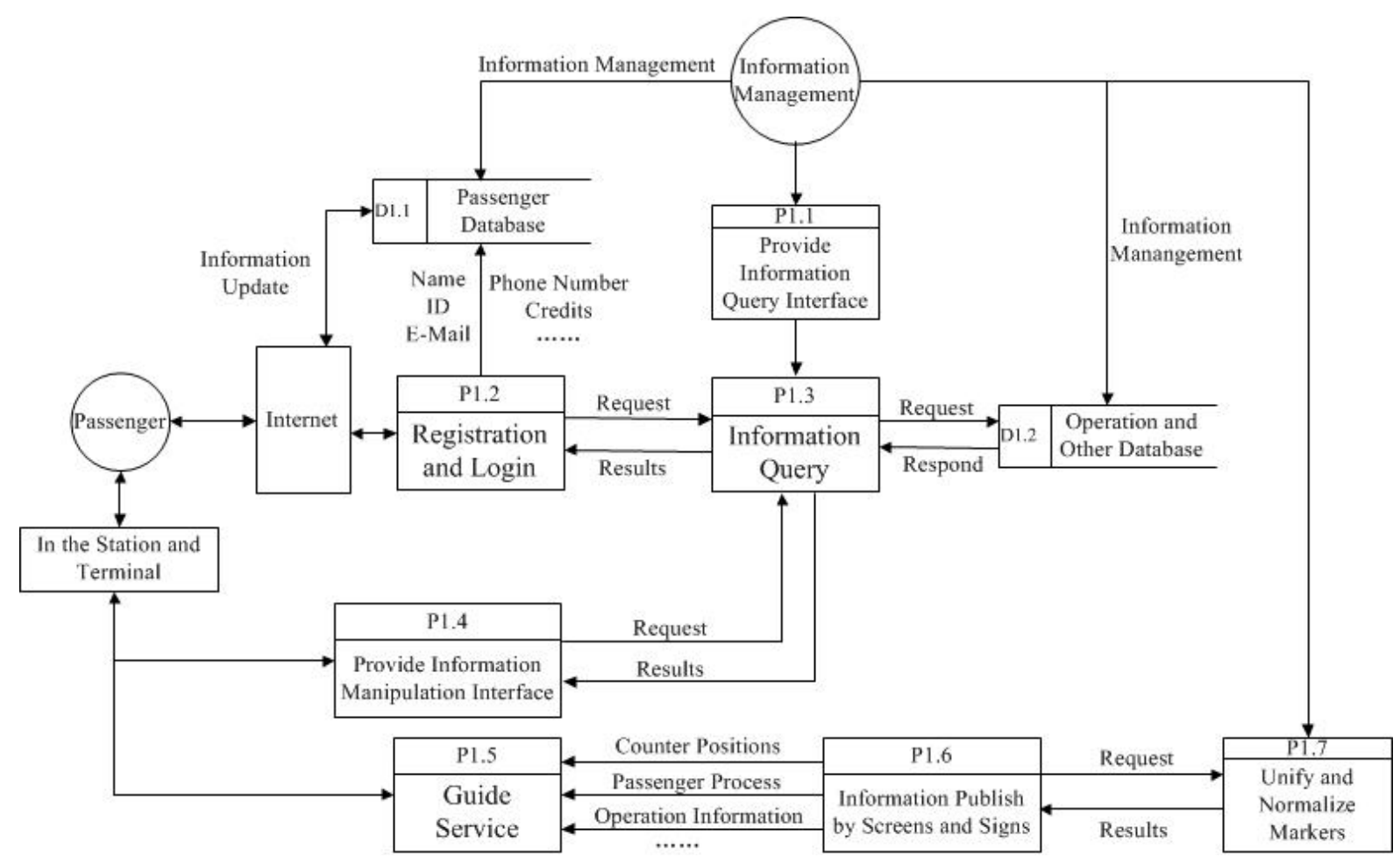

Figure 4. Structure of operation service subsystem.

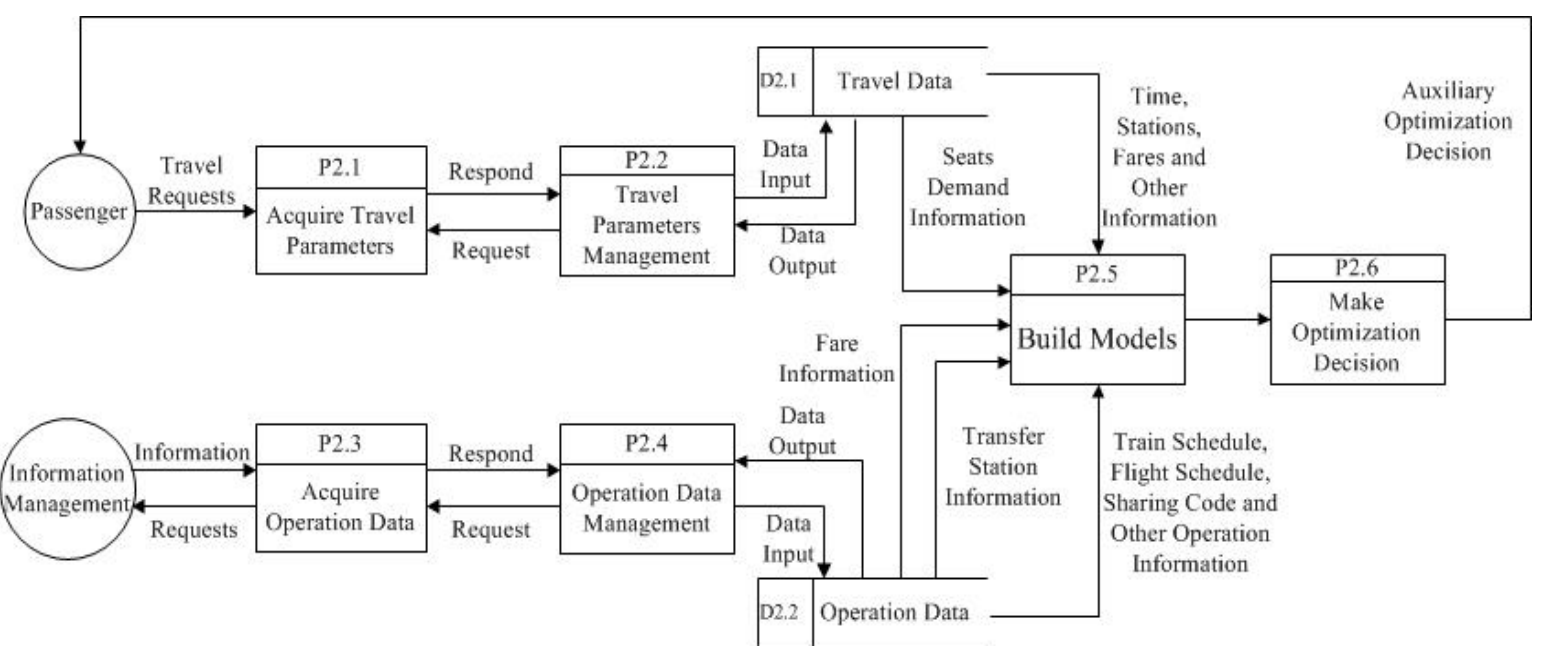

Figure 5. Structure of auxiliary optimization decision subsystem.

\subsection{Through Baggage Handling Subsystem}

The ideal air-rail intermodal should provide through baggage handling service. Passengers could check their baggage after they finish checking in and will arrive in the destination by train and plane without baggage. The through baggage handling subsystem will connect with the Departure Control System and monitor the whole process of baggage transportation. The programs will trace and check the baggage and provide query service for passengers.

In the through baggage handling subsystem, the baggage will get the first security check in the railway station and be delivered to the terminal to get the second security check with other baggage. Because of the higher security standards of civil aviation than that of railway, it's more efficient to adopt the secondary security mode for transport safety. Result is shown in Figure 7. 


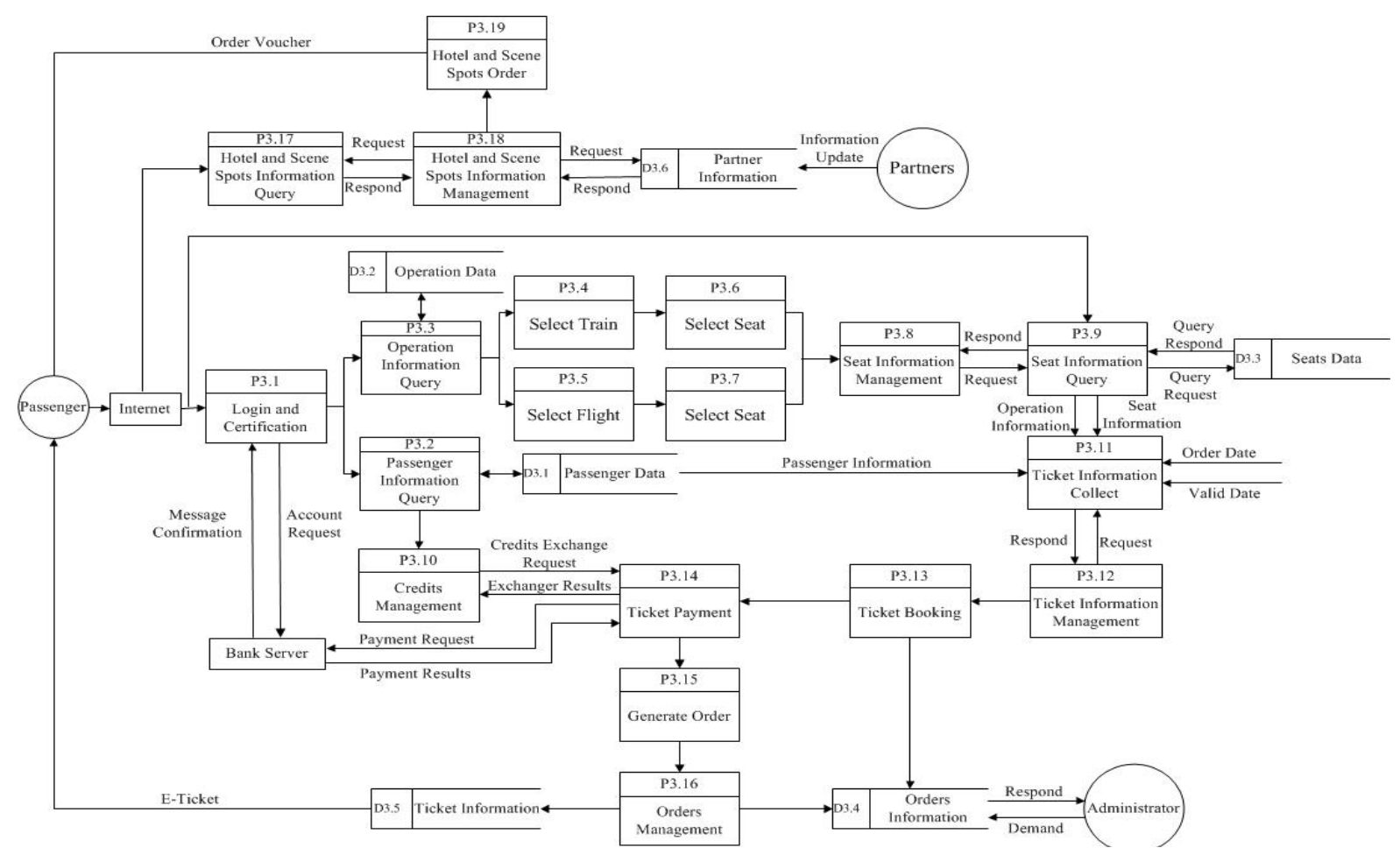

Figure 6. Structure of integrated ticketing subsystem.

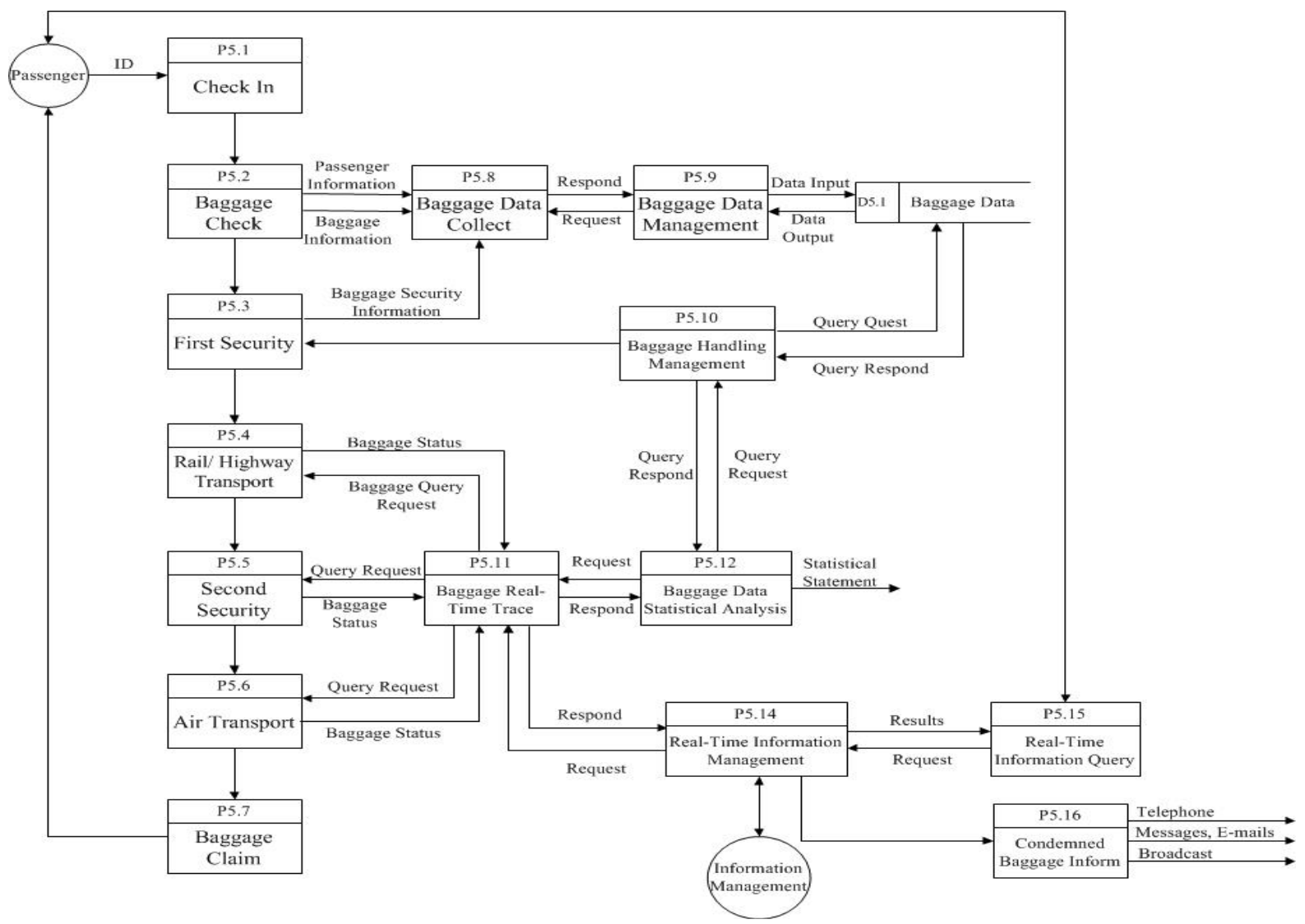

Figure 7. Structure of through baggage handling subsystem. 


\subsection{Feedback Service Subsystem}

To regulate the channels of passenger information feedback and solve in time, and to improve service level, the feedback service subsystem is established to provide a channel to complain and solve problems. Ways of questionnaires and evaluating online are used for feedback opinions statistics. Only relevant staff could have the authorities to inquire the feedback information and contact with passengers to check and trace the solve schedule. In the meanwhile, the opinions are taken to improve service level.

\subsection{Information Management Subsystem}

The administration departments, rail units and civil aviation units can get relevant authorities through information management subsystem, updating and managing their data and information within the permissions. This subsystem establishes interfaces to rail database and civil aviation database respectively to realize data share and real-time exchange on the premise of complete contract mechanism, laws and safety standards. Besides, it could collect passenger information, operation information and other information.

In the meanwhile, the information passengers inquire by operation service subsystem is published by information management subsystem. Therefore, there are 5 functions of information management subsystem: identity verification, data collect and update, data share, information publish and display, information security guarantee.

\subsection{Financial Management Subsystem}

Financial Management Subsystem covers the system management and statistical analysis of fee business, which could store and manage all kinds of financial data and automatically generate statements. It could also provide financial forecast, cost analysis and other economic activities analysis and decision support for air-rail intermodal. Besides, all units can set clearing parameters based on their cost and clearing principles. The subsystem will complete automatic clearing online. The administration department is responsible for maintaining and managing the financial data to guarantee account information safety.

\section{Conclusion}

With the construction of Beijing New Airport, air-rail intermodality will become an important means to promote Jing-Jin-Ji integration development and expand its brand radiation range. This paper provides theory reference for air-rail intermodal development in Jing-Jin-Ji region. The future research emphasis should be standard management and establishment of the air-rail intermodality system on the basis of the actual situation in this region.

\section{References}

[1] Liu, W. (2014) Logical Architecture Framework of Air-Rail Intermodality System. Transportation Enterprise Management, 11, 68-70.

[2] Zhang, X. (2013) Civil Aviation Management Information System. National Defence Industry Press, Beijing.

[3] Jia, L.M., Li, P., Qin, Y. and Shi, T.Y. (2003) Architecture Framework of Railway Intelligent Transport System of China. Chinese Railways, 9, 22-26.

[4] Ren, P., Xu, R.H. and Tao, Y.J. (2009) Construction of Air-Rail Intermodality Information Sharing Platform. Journal of Transport Information and Safety, 1, 109-112. 